\title{
Augmentation index is associated with B-type natriuretic peptide in patients with paroxysmal atrial fibrillation
}

\author{
Youko Kaji $^{1}$, Toru Miyoshi ${ }^{2}$, Masayuki Doi ${ }^{1}$, Satoshi Hirohata ${ }^{2}$, Shigeshi Kamikawa ${ }^{2}$, Kosuke Sakane ${ }^{1}$, \\ Tomoki Kitawaki ${ }^{3}$, Shozo Kusachi ${ }^{3}$, Kengo Fukushima Kusano ${ }^{4}$ and Hiroshi Ito ${ }^{4}$
}

B-type natriuretic peptide (BNP) levels have been shown to be elevated in patients with paroxysmal atrial fibrillation (PAF); however, the underlying mechanisms have not been fully elucidated. Earlier, we reported that an increase in the augmentation index (AI), which is an index of wave reflection and arterial stiffness, is associated with PAF. In this study, we investigate the relationship between the BNP level and Al in patients with PAF. We enrolled 92 patients with a history of PAF and 90 age- and gender-matched individuals without PAF. AI was calculated using applanation tonometry of the radial artery when all patients were on sinus rhythm. Plasma BNP levels were measured simultaneously. An arterial stiffness parameter, the cardio-ankle vascular index (CAVI), was also evaluated. The increased AI in patients with PAF correlated with the elevation of the BNP level $(r=0.47, P<0.01)$. When PAF patients were classified into tertiles on the basis of the BNP level, the left atrial volume index, left ventricular mass index, AI and CAVI increased, and mitral annular $e^{\prime}$ velocity ( $\left.e^{\prime}\right)$, as an index of left ventricular diastolic pressure, decreased with BNP tertiles. Al was also associated with $\mathrm{e}^{\prime}$ and left ventricular mass index. Multiple regression analysis showed that the AI in PAF patients independently correlated with BNP levels. This study showed that AI was an independent correlate of the BNP level in PAF patients. Left ventricular diastolic dysfunction, which linked to an increase in arterial stiffness, may be involved in the elevated BNP level.

Hypertension Research (2009) 32, 611-616; doi:10.1038/hr.2009.62; published online 1 May 2009

Keywords: arterial stiffness; atrial fibrillation; B-type natriuretic peptide; reflection wave

\section{INTRODUCTION}

The B-type natriuretic peptide (BNP) is a neurohormone secreted from cardiac ventricles in response to ventricular volume and pressure overload. ${ }^{1}$ The BNP level does not only significantly correlate with the left ventricular (LV) filling pressure but also reflects symptomatic LV dysfunction and prognosis. ${ }^{2}$ Although BNP has been reported to be an excellent screening tool for LV dysfunction, some patients with paroxysmal atrial fibrillation (PAF) or coronary artery disease have been shown to have a high BNP level, independent of LV systolic function; ${ }^{3,4}$ however, the underlying mechanisms of the increase in BNP level in patients with PAF have not been fully elucidated.

Our recent study showed that the augmentation index (AI) obtained from the radial artery is increased in patients with PAF. ${ }^{5}$ $\mathrm{AI}$, determined from either a directly measured or derived central arterial pressure wave form, has been proposed as a measure of aortic stiffness and wave reflection. ${ }^{6}$ Earlier studies have shown that AI is closely related to several risk factors for atherosclerosis ${ }^{7}$ and cardiovascular diseases. ${ }^{8} \mathrm{AI}$ can be determined noninvasively by pulse wave analysis of the radial artery, and provides information on cardiac load and vascular properties. ${ }^{9,10}$ The usefulness of AI measured from radial pressure waveform has been shown in earlier studies. ${ }^{10,11}$ As another parameter of arterial stiffness, the cardio-ankle vascular index (CAVI), which reflects the stiffness of the aorta independently of blood pressure, has been developed recently. ${ }^{12}$ CAVI was reported to be associated with atherosclerosis, ${ }^{13}$ cardiovascular risk factors ${ }^{14}$ and LV diastolic dysfunction. ${ }^{15}$

From this evidence, we hypothesized that AI is associated with the BNP level in PAF patients. Accordingly, we measured BNP in patients with a history of PAF and analyzed its relationship with AI, along with CAVI and echocardiographic parameters.

\section{METHODS}

Study population

We recruited 92 consecutive patients (43-80 years of age) with a history of PAF (PAF group) and 90 age-matched individuals without a history of PAF (control group), who visited the Sumitomo Besshi hospital from December 2006 to

${ }^{1}$ Department of Internal Medicine, Division of Cardiology, Sumitomo Besshi Hospital, Niihama, Japan; ${ }^{2}$ Department of Molecular Biology and Biochemistry, Okayama University Graduate School of Medicine, Dentistry and Pharmaceutical Sciences, Okayama, Japan; ${ }^{3}$ Department of Medical Technology, Okayama University Graduate School of Health Sciences, Okayama, Japan and ${ }^{4}$ Department of Cardiovascular Medicine, Okayama University Graduate School of Medicine, Dentistry and Pharmaceutical Sciences, Okayama, Japan Correspondence: Dr T Miyoshi, Department of Molecular Biology and Biochemistry, Okayama University Graduate School of Medicine, Dentistry and Pharmaceutical Sciences, 2-5-1, Shikata-cho, Okayama 700-8558, Japan.

E-mail: torumiyoshi@hotmail.com

Received 6 January 2009; revised 6 April 2009; accepted 7 April 2009; published online 1 May 2009 
November 2007. PAF was diagnosed according to the ACC/AHA/ESC 2006 Guidelines. ${ }^{16}$ All individuals were in sinus rhythm at the time of measuring the $\mathrm{AI}$ and blood sampling. Hypertension was diagnosed in accordance with the 1999 World Health Organization-International Society of Hypertension Guidelines for the management of hypertension. ${ }^{17}$ Diabetes mellitus was defined as a fasting blood glucose level $>126 \mathrm{mg}$ per $100 \mathrm{ml}$ or that requiring antidiabetic medication. Hyperlipidemia was defined as a total cholesterol level of $>220 \mathrm{mg}$ per $100 \mathrm{ml}$ or that requiring antihyperlipidemic medication. Exclusion criteria were as follows: (1) patients with cardiomyopathy; (2) patients with renal insufficiency (serum creatinine more than $1.5 \mathrm{mg} \mathrm{ml}^{-1}$ ); (3) those with acute coronary syndrome; (4) patients with prosthetic valves or mitral stenosis and (5) those with decreased LV systolic function (LV ejection fraction $<50 \%$ ), because modification of the cardiac ejection pattern owing to a low LV function may alter AI. ${ }^{18,19}$ This study protocol complied with the Declaration of Helsinki and was approved by the ethics committee of the Sumitomo Besshi Hospital. Informed consent was obtained from all patients before the study. ${ }^{20}$

\section{Radial pulse wave analysis}

All measurements were determined in a quiet room kept at constant temperature. First, after a 5-min rest and with the individual seated, brachial blood pressure was measured using an automatic cuff oscillometric device (HEM-907; Omron Healthcare Co. Ltd, Kyoto, Japan). ${ }^{11}$ The average of two readings was used to determine systolic pressure, diastolic pressure, mean arterial pressure and pulse pressure. Next, the radial pulse wave was determined at the wrist using applanation tonometry with a high-fidelity micromanometer (HEM-9000AI; Omron Healthcare Co. Ltd), as described earlier. ${ }^{10,15}$

\section{Cardio-ankle vascular index}

The CAVI in patients with PAF was simultaneously measured. CAVI was measured automatically using a VaSera VS-1000 (Fukuda Denshi, Tokyo, Japan) from the measurement of blood pressure and pulse wave velocity (PWV), while monitoring the electrocardiogram and heart sounds. ${ }^{12,15} \mathrm{PWV}$ was calculated by dividing the distance from the aortic valve to the ankle artery by the sum of the time between the aortic valve closing sound and the notch of the brachial pulse wave, and the time between the rise of the brachial pulse wave and the ankle pulse wave. CAVI was determined using the following equation: $\mathrm{CAVI}=a\left((2 \rho / \Delta \mathrm{P}) \times \ln (\mathrm{Ps} / \mathrm{Pd}) \times \mathrm{PWV}^{2}\right)+b$, where $\mathrm{Ps}$ and $\mathrm{Pd}$ are systolic and diastolic blood pressures, respectively, PWV is the pulse wave velocity between the heart and ankle, $\Delta \mathrm{P}$ is $\mathrm{Ps}-\mathrm{Pd}$, where $\rho$ is blood density and a and $\mathrm{b}$ are constants. The average of right and left CAVI was used for analysis.

\section{B-type natriuretic peptide measurement}

Blood for measuring the BNP level was collected in the fasting state in EDTAtreated tubes on the day when echocardiography was carried out. After centrifugation at 2500 r.p.m. and $4{ }^{\circ} \mathrm{C}$, the plasma was stored at $-80^{\circ} \mathrm{C}$. Plasma BNP was determined by immunoradiometric assay (non-extracted) using an antibody to human BNP (Shionogi Co. Ltd, Tokyo, Japan), as described earlier. ${ }^{10}$ The precision, analytical sensitivity and stability characteristics of the system have been described earlier. ${ }^{1}$

\section{Transthoracic echocardiography}

Comprehensive transthoracic echocardiography was carried out using commercially available equipment (iE33; Philips, Andover, MA, USA). Standard M mode, two dimensional and color Doppler imaging were carried out in parasternal and apical views. Measurements were made according to the guidelines laid down by the American Society of Echocardiography. ${ }^{21}$ The left atrial volume index (LAVI) was assessed by the modified biplane area-length method $^{22}$ and was indexed to the body surface area. LV ejection fraction was measured using the modified Simpson rule. LV mass was calculated using the Penn convention. ${ }^{23}$ The left ventricular mass index (LVMI) was calculated by dividing LV mass by the body surface area. The LV diastolic filling pattern was recorded from the apical transducer position, with the sample volume situated between the mitral leaflet tips. Peak early diastolic velocity (E velocity) and peak atrial diastolic velocity (A velocity) were recorded, and the ratio of $\mathrm{E}$ to $\mathrm{A}(\mathrm{E} / \mathrm{A})$ was calculated. The deceleration time of $\mathrm{E}$ velocity (DcT) was measured as the time interval from the E-wave peak to the decline of velocity to baseline values.
The tissue Doppler-derived diastolic mitral annular velocity (e') was also obtained.

\section{Statistical analysis}

Categorical variables were compared between groups by $\chi^{2}$-analysis. The unpaired Student's test was used for continuous variables between groups. Differences in characteristics across BNP tertiles were compared by one-way ANOVA (analysis of variance), followed by Bonferroni's post hoc test for continuous variables. Differences in parameters between PAF and control groups or among BNP tertiles were also evaluated after adjustment for several factors by ANCOVA (analysis of covariance). The correlation between the AI or the BNP level and other clinical parameters was examined by univariate and multivariate linear regression analysis. As the BNP level was not normally distributed, the log-transformed BNP level $(\log \mathrm{BNP})$ was used in linear regression analysis. Differences at $P<0.05$ were considered significant. Data were analyzed using SPSS 11.0 for Windows (SPSS Inc., Chicago, IL, USA).

\section{RESULTS}

\section{BNP level and AI in patients with and without PAF}

Table 1 shows the characteristics of all patients in this study, according to their PAF history. There were no differences in the prevalence of hypertension and diabetes, although hyperlipidemia was more prevalent in patients without PAF. Patients with PAF used $\beta$-blockers, digitalis and antiarrythmic drugs more frequently than did individualss without PAF. Left atrial diameter and LVMI in patients with PAF were significantly greater than those in patients without PAF. The crude AI in PAF patients showed a significantly higher value than that

Table 1 Comparison of clinical characteristics in patients with or without PAF

\begin{tabular}{|c|c|c|c|}
\hline & Control $(n=90)$ & $\operatorname{PAF}(\mathrm{n}=92)$ & P-value \\
\hline Age (years) & $69 \pm 7$ & $70 \pm 8$ & 0.27 \\
\hline $\operatorname{Men}(n, \%)$ & $50(57)$ & $55(60)$ & 0.56 \\
\hline Height $(\mathrm{cm})$ & $159 \pm 8$ & $160 \pm 7$ & 0.18 \\
\hline BMI $\left(\mathrm{kg} \mathrm{m}^{-2}\right)$ & $23.6 \pm 3.1$ & $23.5 \pm 3.4$ & 0.79 \\
\hline Heart rate (b.p.m.) & $70 \pm 10$ & $64 \pm 10$ & $<0.01$ \\
\hline Hypertension $(n, \%)$ & $57(63)$ & $49(53)$ & 0.16 \\
\hline Hyperlipidemia ( $n, \%)$ & $44(49)$ & $27(29)$ & 0.01 \\
\hline Diabetes $(n, \%)$ & $14(16)$ & $16(17)$ & 0.74 \\
\hline History of CAD ( $n, \%)$ & $15(17)$ & $9(10)$ & 0.16 \\
\hline History of smoking $(n, \%)$ & $14(16)$ & $11(12)$ & 0.56 \\
\hline $\mathrm{SBP}(\mathrm{mm} \mathrm{Hg})$ & $135 \pm 14$ & $135 \pm 18$ & 0.97 \\
\hline $\mathrm{DBP}(\mathrm{mm} \mathrm{Hg})$ & $73 \pm 10$ & $73 \pm 10$ & 0.95 \\
\hline Pulse pressure $(\mathrm{mm} \mathrm{Hg})$ & $63 \pm 11$ & $62 \pm 15$ & 0.85 \\
\hline Creatinine (mg per $100 \mathrm{ml}$ ) & $0.8 \pm 0.3$ & $0.8 \pm 0.2$ & 0.17 \\
\hline \multicolumn{4}{|l|}{ Medications ( $n, \%)$} \\
\hline ACEI/ARB & 35 (39) & $30(33)$ & 0.38 \\
\hline $\mathrm{CCB}$ & $27(30)$ & $35(38)$ & 0.25 \\
\hline$\beta$-Blockers & $5(6)$ & $20(22)$ & $<0.01$ \\
\hline Digitalis & $2(2)$ & $15(16)$ & $<0.01$ \\
\hline Antiarrythmic drugs & $1(1)$ & $51(55)$ & $<0.01$ \\
\hline LVEF (\%) & $71 \pm 8$ & $71 \pm 8$ & 0.63 \\
\hline LAD (mm) & $34.7 \pm 4.8$ & $38.1 \pm 5.6$ & $<0.01$ \\
\hline LVMI $\left(\mathrm{g} \mathrm{m}^{-2}\right)$ & $91.3 \pm 20.1$ & $99.8 \pm 25.5$ & 0.02 \\
\hline $\mathrm{Al}(\%)$ & $81.0 \pm 10.4$ & $89.1 \pm 11.5$ & $<0.01$ \\
\hline $\mathrm{BNP}\left(\mathrm{pg} \mathrm{ml^{-1 } )}\right.$ & $26.3 \pm 27.4$ & $54.2 \pm 57.9$ & $<0.01$ \\
\hline
\end{tabular}

Abbreviations: ACEls, angiotensin-converting enzyme inhibitors; Al, augmentation index; ARBs, angiotensin receptor blockers; BNP, B-type natriuretic peptide; BMI, body mass index; CAD, angiotensin receptor blockers; BNP, B-type natriuretic peptide; BMI, body mass index; CAD,
coronary artery disease; CCBs, calcium channel blockers; DBP, diastolic blood pressure; LVEF, coronary artery disease; CCBs, calcium channel blockers; DBP, diastolic blood pressure; LVEF,
left ventricular ejection fraction; LVMI, left ventricular mass index; SBP, systolic blood pressure. Values are expressed as numbers with percentages in parentheses or as the mean \pm s.d. 
in individuals without PAF. This difference remained significant after adjustment for confounding factors such as age, gender, height, heart rate, use of antiarrythmic drugs and the presence of hyperlipidemia $(88.0 \pm 1.1$ and $82.1 \pm 1.1 \%$, respectively, expressed as the mean \pm s.e., $P<0.01)$. The crude BNP level in patients with PAF was shown to be higher than that in individuals without PAF, even after adjustment for the confounding factors mentioned above (51.6 \pm 4.7 and $28.9 \pm 4.8 \mathrm{pg} \mathrm{ml}^{-1}$, respectively, expressed as the mean \pm s.e., $P<0.01)$. Next, we carried out an additional analysis by excluding patients on $\beta$-blockers and on digitalis, because it is well known that slowing of the heart rate may increase AI. In the comparison between individuals with PAF $(n=59)$ and those without PAF $(n=89)$, the difference in AI between the two groups was shown to be significant even after adjustment of age, gender and height $(87.8 \pm 1.3 \mathrm{vs}$. $81.6 \pm 1.0 \%$, respectively, expressed as the mean \pm s.e., $P<0.01)$.

\section{Relationship between AI and clinical characteristics}

To assess the factors affecting AI and BNP, univariate and multivariate linear regression analyses were carried out according to the history of PAF (Table 2 and Figure 1). Multivariate analysis showed that the AI in patients with PAF, and not in individuals without PAF, was positively correlated with $\log$ BNP, besides systolic blood pressure (SBP), heart rate and E/A. Furthermore, we carried out an analysis by excluding PAF patients on $\beta$-blockers and on digitalis $(n=59)$. In PAF patients who were not on $\beta$-blockers and digitalis, univariate analysis showed that the AI was correlated with $\log \mathrm{BNP}(r=0.31, P<0.01)$. Multivariate analysis showed again the significant relationship between AI and $\log$ BNP, even after adjusting for covariates such as age, gender, height, heart rate, SBP, left atrial diameter, LVMI and E/A $(\beta=0.16$, $P=0.03)$. Next, as CAVI values were available only in PAF patients, the relationship between CAVI and clinical characteristics in PAF patients was analyzed. Univariate analysis showed that CAVI was significantly correlated with age $(r=0.41, P<0.01)$, SBP $(r=0.26, P<0.01)$, pulse pressure $(r=0.35, P<0.01), \mathrm{E} / \mathrm{A}(r=-0.35, P<0.01)$ and $\log \mathrm{BNP}$

Table 2 Univariate and multivariate relation between Al and clinical characteristics

\begin{tabular}{|c|c|c|c|c|c|c|c|c|}
\hline \multirow{3}{*}{$\begin{array}{l}\text { Dependent } \\
\text { variable: } \\
\text { Al }\end{array}$} & \multicolumn{4}{|c|}{ Patients without PAF } & \multicolumn{4}{|c|}{ Patients with PAF } \\
\hline & \multicolumn{2}{|c|}{ Univariate } & \multicolumn{2}{|c|}{ Multivariate } & \multicolumn{2}{|c|}{ Univariate } & \multicolumn{2}{|c|}{ Multivariate } \\
\hline & $\gamma$ & $\mathrm{P}$-value & $\beta$ & $\mathrm{P}$-value & $\gamma$ & $\mathrm{P}$-value & $\beta$ & $\mathrm{P}$-value \\
\hline Age & 0.25 & 0.02 & -0.05 & 0.70 & 0.13 & 0.20 & -0.11 & 0.26 \\
\hline Male & -0.08 & 0.43 & - & - & -0.15 & 0.16 & - & - \\
\hline Height & -0.22 & 0.04 & -0.24 & 0.03 & -0.26 & 0.01 & -0.17 & 0.10 \\
\hline BMI & 0.01 & 0.93 & - & - & -0.14 & 0.20 & - & - \\
\hline SBP & 0.43 & $<0.01$ & 0.39 & $<0.01$ & 0.28 & $<0.01$ & 0.22 & 0.02 \\
\hline DBP & 0.05 & 0.64 & - & - & -0.01 & 0.99 & - & - \\
\hline Pulse pressure & 0.23 & 0.03 & - & - & 0.15 & 0.16 & - & - \\
\hline Heart rate & -0.40 & $<0.01$ & -0.40 & $<0.01$ & -0.43 & $<0.01$ & -0.31 & $<0.01$ \\
\hline LVEF & -0.13 & 0.25 & - & - & -0.03 & 0.76 & - & - \\
\hline LAD & 0.23 & 0.03 & 0.02 & 0.88 & 0.26 & 0.01 & -0.02 & 0.87 \\
\hline LVMI & 0.23 & 0.03 & -0.11 & 0.32 & 0.29 & $<0.01$ & 0.06 & 0.96 \\
\hline$E / A$ & -0.26 & 0.02 & -0.28 & 0.01 & -0.28 & $<0.01$ & -0.22 & 0.03 \\
\hline DcT & 0.15 & 0.17 & - & - & 0.04 & 0.70 & - & - \\
\hline Log BNP & 0.15 & 0.17 & - & - & 0.47 & $<0.01$ & 0.37 & $<0.01$ \\
\hline
\end{tabular}

Abbreviations: A, peak late diastolic transmitral velocity; BNP, B-type natriuretic peptide; $\mathrm{BMI}$, body mass index; DCT, deceleration time of $\mathrm{E}$ velocity; E, peak early transmitral velocity; Al, augmentation index; DBP, diastolic blood pressure; LAD, left atrial diameter; LVEF, left ventricular ejection fraction; LVMI, left ventricular mass index; SBP, systolic blood pressure.
( $r=0.39, P<0.01$ ), and tended to be associated with height $(r=-0.20$, $P=0.06)$ and LVMI $(r=0.21, P=0.05)$. Multivariate linear regression analyses showed that E/A was significantly correlated with CAVI, although the associations between CAVI and age $(\beta=0.20, P=0.07)$, height $(\beta=0.10, P=0.46)$, pulse pressure $(\beta=0.20, P=0.06)$, LVMI $(\beta=0.16, P=0.06)$ and $\log \mathrm{BNP}(\beta=0.15, P=0.20)$ were not significant. The correlation between AI and CAVI was significant in PAF patients $(r=0.28, P<0.01)$.

\section{Clinical characteristics of PAF patients}

To assess the factors determining BNP levels in PAF patients, the patients were classified on the basis of tertiles of BNP level (Table 3). Women were most prevalent in the highest BNP tertile. There were no differences in the prevalence of hypertension, hyperlipidemia and diabetes, and in the medication for hypertension and arrhythmia among tertiles. Regarding the parameters of blood pressure, there were no differences in SBP and DBP (diastolic blood pressure); however, pulse pressure was significantly greater in the highest BNP tertile than in other tertiles. As for echocardiographic parameters, there were no differences in the LV ejection fraction among groups, whereas the patients in the highest tertile group had a significantly larger LAVI and LVMI, and smaller $e^{\prime}$. The linear regression analysis also showed that $\log$ BNP was correlated with pulse pressure $(r=0.28, P<0.01)$ LAVI $(r=0.37, P<0.01)$, LVMI $(r=0.35, P<0.01)$ and $\mathrm{e}^{\prime} \quad(r=-0.39$, $P<0.01)$ (Figure 1$)$. The crude AI increased with BNP tertiles, and this difference remained significant after adjusting for age, gender and pulse pressure among the lowest, middle and the highest BNP tertiles $(84.9 \pm 2.0,87.5 \pm 1.9$ and $94.9 \pm 2.0 \%$, respectively, expressed as the means \pm s.e., $P<0.01)$. Crude CAVI significantly increased with BNP tertiles, whereas the difference in CAVI after adjustment for confounding factors did not reach statistical significance $(P=0.07)$.

\section{Assessments of clinical characteristics affecting BNP level in patients with PAF}

Stepwise multiple linear regression analyses showed that among variables, AI, LVMI and male gender were independent correlates of increased BNP levels in PAF patients (Table 4).

\section{Comparisons of BNP levels, CAVI, AI and clinical and} echocardiographic parameters between patients with normal LAVI and those with increased LAVI

Increased LAVI was defined as greater than or equal to $28 \mathrm{ml} \mathrm{m}^{-2}$. Age, $\mathrm{e}^{\prime}, \mathrm{E} / \mathrm{A}, \mathrm{DcT}, \mathrm{CAVI}, \mathrm{AI}$ and BNP levels showed significant differences between patients with normal LAVI and those with increased LAVI (Table 5). There were no differences in SBP, DBP, heart rate and LVMI.

\section{DISCUSSION}

In this study, we showed that an elevated AI was independently associated with the increase in BNP levels in patients with a history of PAF. Taken together with the echocardiographic finding that AI was correlated with the parameters of diastolic function, the BNP level in PAF patients may reflect LV diastolic dysfunction linked to an increase in arterial stiffness. In addition, AI and CAVI in patients with larger LAVI were greater than those in patients with normal LAVI, even though the LVMI was not different between groups. These findings suggest that arterial stiffness is more severe in PAF patients and the development of PAF may be involved in increased arterial stiffness.

In our study, a significant association between the AI and BNP level was observed in PAF patients, but not in individuals without PAF, although earlier studies showed a significant correlation between the $\mathrm{BNP}$ level and $\mathrm{AI}$ in hypertensive patients. ${ }^{24}$ One explanation for this 

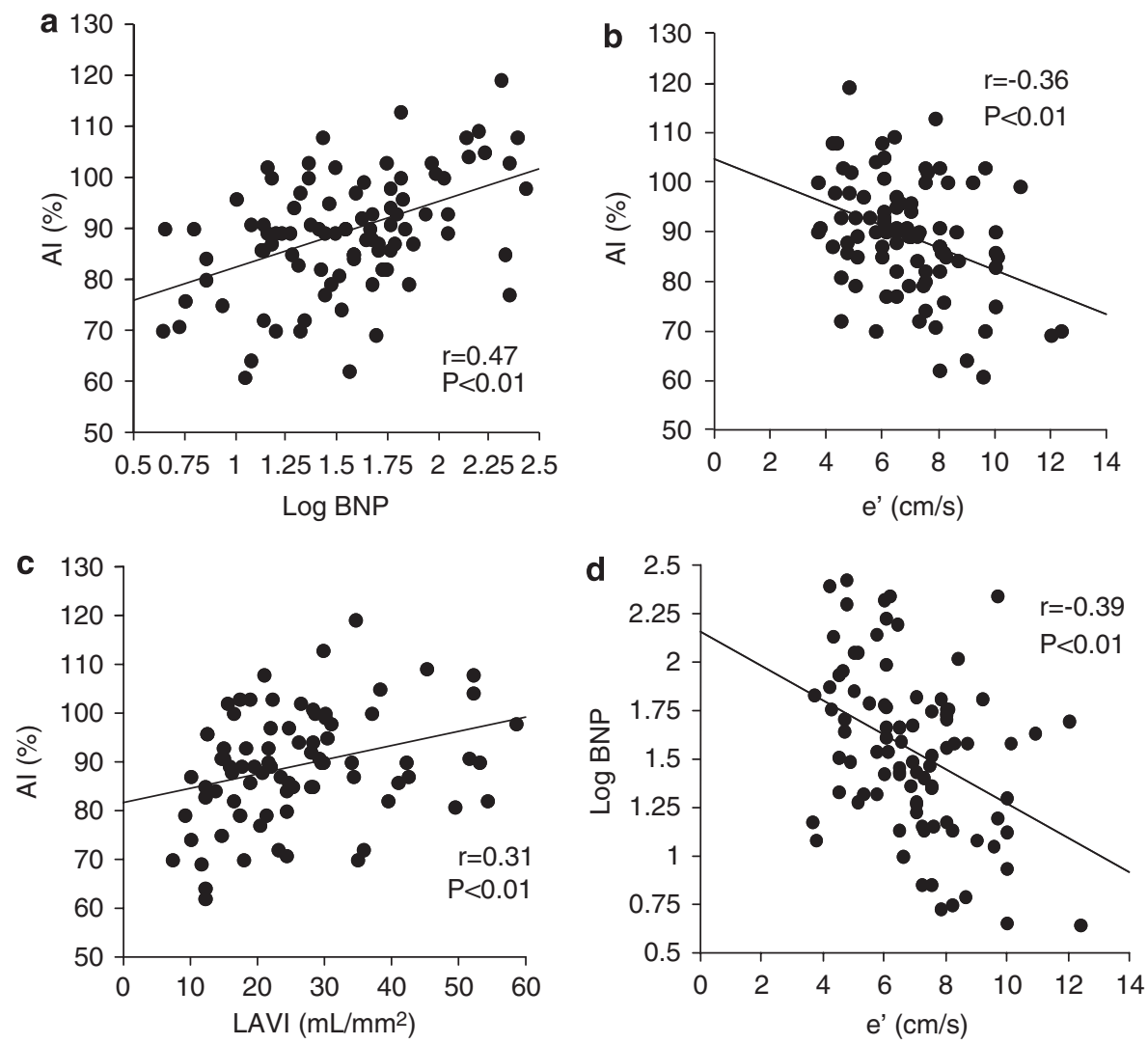

Figure 1 The correlation between the augmentation index (AI) and log-transformed BNP (a), e' (b) and LAVI (c), and the correlation between log-transformed BNP and $e^{\prime}(d)$, in patients with PAF.

discrepancy is that our control group included around 40\% nonhypertensive patients. Another explanation is that a relatively older population was enrolled in this study. An earlier large cohort study in healthy individuals suggested that the increase in AI with age became obscure after the age of 60 years. ${ }^{25}$ Despite the factors influencing AI, we found a significant association between BNP and AI in PAF patients.

Augmentation index has been shown to be affected by various clinical factors, such as heart rate, LV function, gender, age and antihypertensive medicines. ${ }^{18,25,26}$ In this study, even after adjustment for those factors, the difference in AI between patients with or without PAF remained significant. In the analysis of PAF patients, heart rate, age and medications did not differ among the tertiles of the BNP level, and this study did not include patients with a decreased LV ejection fraction. Therefore, age, medication and LV systolic function were thus not responsible for the present finding of a relationship between AI and the BNP level. Multivariate analysis finally selected AI as an independent factor associated with BNP level in PAF patients, as LV diastolic function representing $\mathrm{e}^{\prime}$ differed among the tertiles of the BNP level.

Regarding the underlying mechanisms of the association between $\mathrm{AI}$ and BNP level, an explanation is that AI may contribute to diastolic dysfunction and lead to the elevation of the BNP level. An enhanced arterial stiffness increases the velocity of the pulse wave generated by LV ejection (pulse wave velocity), and the reflected wave returns early to the heart, which enhances pressure augmentation. An increase in the afterload may then result in myocardial structural changes in the $\mathrm{LV}$, such as hypertrophy and diastolic dysfunction. In fact, earlier studies showed that an increase in AI, which increases with late systolic peak pressure, was associated with echocardiographic parameters regarding LV relaxation in individuals with a preserved LV ejection fraction. 24,27,28 Another explanation is that an increase in AI was involved in LV hypertrophy, which elevates the LV pressure and leads to the elevation of BNP level. Consistant with this relationship, several reports have shown that $\mathrm{AI}$ is an important determinant of LV mass. ${ }^{29}$

In this study, the BNP level in PAF patients was significantly correlated with AI and CAVI. Both the parameters may be affected by arterial structure and function, whereas the theoretical concept and the confounding factors of the two measurements are not the same. AI is considered as a parameter of peripheral wave reflection as well as of large-artery stiffness. The important factors for AI are not only fast pulse wave velocity through stiff arteries, but also sites of impedance mismatch at the periphery. On the other hand, CAVI essentially represents stiffness of the aorta, the femoral artery and the tibial artery as a whole. ${ }^{12}$ There are emerging clinical evidences for a theoretical rationale for CAVI in determining vascular function, as CAVI was shown to be correlated with the stiffness parameter beta of the thoracic descending aorta obtained with transesophageal echocardiography. ${ }^{30}$ Hence, with regard to large artery stiffness, CAVI could support, at least in part, the preset result regarding the relationship between BNP level and AI in patients with PAF.

In this study, we showed that increased LAVI in PAF patients was correlated with enhanced arterial stiffness presented by AI and CAVI. An earlier study showed that left atrial enlargement was an important precursor of atrial fibrillation $(\mathrm{AF}) .^{31}$ We have also reported the increase in $\mathrm{AI}$ and LA sizes as a potential risk for PAF. ${ }^{5}$ Increased AI would result in anatomical changes and electrophysiological alterations in LA, which may provide a basis for the increased incidence 
Table 3 Association between plasma BNP level and covariates among study groups

\begin{tabular}{|c|c|c|c|c|}
\hline & \multicolumn{4}{|c|}{$B N P\left(p g t^{-1}\right)$} \\
\hline & $T 1(\mathrm{n}=30)$ & $T 2(n=31)$ & $T 3(n=31)$ & P-value \\
\hline Age (years) & $67 \pm 9$ & $71 \pm 7$ & $72 \pm 7$ & 0.07 \\
\hline Men $(n, \%)$ & $23(77)$ & $19(61)$ & $13(42)$ & 0.02 \\
\hline Height $(\mathrm{cm})$ & $162 \pm 6$ & $160 \pm 7$ & $160 \pm 7$ & 0.27 \\
\hline BMI $\left(\mathrm{kg} \mathrm{m}^{-2}\right)$ & $24.2 \pm 2.7$ & $22.8 \pm 3.8$ & $23.5 \pm 3.4$ & 0.26 \\
\hline Hypertension ( $n, \%)$ & $15(43)$ & $17(55)$ & $17(61)$ & 0.90 \\
\hline Hyperlipidemia ( $n, \%)$ & $12(40)$ & $7(23)$ & $8(26)$ & 0.28 \\
\hline Diabetes $(n, \%)$ & $4(13)$ & $6(19)$ & $6(19)$ & 0.77 \\
\hline History of CAD $(n, \%)$ & $4(13)$ & $2(7)$ & $3(10)$ & 0.66 \\
\hline History of smoking $(n, \%)$ & $6(20)$ & $3(10)$ & $5(16)$ & 0.52 \\
\hline $\mathrm{SBP}(\mathrm{mm} \mathrm{Hg})$ & $132 \pm 16$ & $135 \pm 12$ & $139 \pm 22$ & 0.28 \\
\hline $\mathrm{DBP}(\mathrm{mm} \mathrm{Hg})$ & $76 \pm 11$ & $73 \pm 9$ & $71 \pm 11$ & 0.11 \\
\hline Pulse pressure $(\mathrm{mm} \mathrm{Hg})$ & $56 \pm 12$ & $62 \pm 13$ & $68 \pm 19$ & $<0.01$ \\
\hline Heart rate (b.p.m.) & $66 \pm 9$ & $66 \pm 11$ & $62 \pm 8$ & 0.13 \\
\hline \multicolumn{5}{|l|}{ Medications ( $n, \%)$} \\
\hline ACEI/ARB & $7(23)$ & $11(35)$ & $12(39)$ & 0.40 \\
\hline $\mathrm{CCB}$ & $7(23)$ & $16(51)$ & $12(39)$ & 0.08 \\
\hline$\beta$-Blockers & $6(20)$ & $4(13)$ & $10(32)$ & 0.17 \\
\hline Digitalis & $4(13)$ & $8(26)$ & $3(10)$ & 0.20 \\
\hline Antiarrythmic drugs & $16(53)$ & $16(52)$ & $19(61)$ & 0.71 \\
\hline $\operatorname{LVEF}(\%)$ & $70 \pm 8$ & $70 \pm 9$ & $72 \pm 7$ & 0.75 \\
\hline LAVI $\left(\mathrm{ml} \mathrm{m}^{-2}\right)$ & $20.7 \pm 8.2$ & $25.7 \pm 12.0$ & $30.6 \pm 13.3$ & 0.01 \\
\hline LVMI $\left(\mathrm{g} \mathrm{m}^{-2}\right)$ & $90.3 \pm 24.0$ & $100.8 \pm 26.0$ & $108.1 \pm 24.1$ & 0.02 \\
\hline $\mathrm{e}^{\prime}\left(\mathrm{cm} \mathrm{s}^{-1}\right)$ & $7.8 \pm 2.0$ & $6.9 \pm 1.7$ & $6.1 \pm 1.6$ & $<0.01$ \\
\hline$E / A$ & $0.84 \pm 0.19$ & $0.81 \pm 0.17$ & $0.78 \pm 0.15$ & 0.34 \\
\hline CAVI & $8.5 \pm 1.1$ & $9.7 \pm 0.9$ & $9.5 \pm 0.8$ & $<0.01$ \\
\hline $\mathrm{Al}(\%)$ & $83.7 \pm 10.6$ & $87.5 \pm 10.3$ & $96.0 \pm 10.3$ & $<0.01$ \\
\hline $\mathrm{BNP}\left(\mathrm{pg} \mathrm{ml}^{-1}\right)$ & $12.8 \pm 5.1$ & $35.1 \pm 9.3$ & $113.2 \pm 66.1$ & $<0.01$ \\
\hline
\end{tabular}

Abbreviations: A, peak late diastolic transmitral velocity; ACEls, angiotensin-converting enzyme inhibitors; AI, augmentation index; ARBs, angiotensin receptor blockers; BNP, B-type natriuretic peptide; BMI, body mass index; CAD, coronary artery disease; CCBs, calcium channel blockers; DBP, diastolic blood pressure; E, peak early transmitral velocity; LVEF, left ventricular ejection fraction; LVMI, left ventricular mass index; SBP, systolic blood pressure.

Table 4 Stepwise multiple regression analysis variables associated with BNP level in PAF patients

\begin{tabular}{llcrl}
\hline $\begin{array}{l}\text { Dependent } \\
\text { variable }\end{array}$ & $\begin{array}{l}\text { Explanatory } \\
\text { variable }\end{array}$ & $\begin{array}{c}\text { Standardized regression } \\
\text { coefficient }\end{array}$ & $\mathrm{t}$ & P-value \\
\hline Log BNP & $\mathrm{Al}$ & 0.356 & 3.47 & 0.001 \\
& LVMI & 0.248 & 2.50 & 0.015 \\
& Gender (male) & -0.227 & -2.30 & 0.024 \\
\hline
\end{tabular}

Abbreviations: AI, augmentation index; BNP, B-type natriuretic peptide; LVMI, left ventricular mass index; PAF, paroxysmal atrial fibrillation.

Multiple regression coefficient $r=0.584, P<0.01$.

of AF. Thus, AI would be clinically useful to some extent for assessing PAF patients in connection with LA size, as AI measurement is easy and noninvasive.

This study has several limitations. First, because patients were recruited from the outpatient cardiology clinic, invasive hemodynamic measurement to obtain precise data, including cardiac catheterization, was not carried out. To make up for this limitation, extensive Doppler echocardiographic assessments and measurement of atrial volume were carried out. Second, because this is a cross-sectional study, the causal relationship could not be clarified. A prospective study is
Table 5 Comparison of clinical characteristics in PAF patients with normal or increased left atrial volume index

\begin{tabular}{|c|c|c|c|}
\hline & Normal LAVI $(\mathrm{n}=59)$ & Increased LAVI $(\mathrm{n}=33)$ & P-value \\
\hline Age (years) & $69 \pm 8$ & $72 \pm 7$ & 0.04 \\
\hline $\mathrm{SBP}(\mathrm{mm} \mathrm{Hg})$ & $134 \pm 19$ & $138 \pm 17$ & 0.34 \\
\hline $\mathrm{DBP}(\mathrm{mm} \mathrm{Hg})$ & $74 \pm 10$ & $73 \pm 11$ & 0.61 \\
\hline Heart rate (b.p.m.) & $65 \pm 10$ & $63 \pm 9$ & 0.18 \\
\hline $\mathrm{e}^{\prime}\left(\mathrm{cm} \mathrm{s}^{-1}\right)$ & $7.3 \pm 1.8$ & $6.2 \pm 1.8$ & $<0.01$ \\
\hline $\mathrm{E} / \mathrm{A}$ & $0.84 \pm 0.18$ & $0.76 \pm 0.14$ & 0.03 \\
\hline DcT (ms) & $196 \pm 32$ & $206 \pm 40$ & 0.23 \\
\hline LVEF (\%) & $71 \pm 8$ & $71 \pm 6$ & 0.92 \\
\hline LVMI $\left(\mathrm{g} \mathrm{m}^{-2}\right)$ & $96.9 \pm 26.3$ & $105.0 \pm 23.7$ & 0.15 \\
\hline CAVI & $8.7 \pm 1.0$ & $9.3 \pm 1.1$ & 0.03 \\
\hline $\mathrm{Al}(\%)$ & $86.9 \pm 11.2$ & $93.2 \pm 11.2$ & 0.01 \\
\hline $\mathrm{BNP}\left(\mathrm{pg} \mathrm{ml^{-1 }}\right)$ & $40.5 \pm 44.7$ & $78.5 \pm 70.5$ & $<0.01$ \\
\hline
\end{tabular}

Abbreviations: A, peak late diastolic transmitral velocity; AI, augmentation index; BNP, B-type natriuretic peptide; CAVI, cardio-ankle vascular index; DBP, diastolic blood pressure; DcT, deceleration time of $E$ velocity; $E$, peak early transmitral velocity; LVEF, left ventricular ejection fraction; LVMI, left ventricular mass index; SBP, systolic blood pressure.

required to clarify the mechanisms. Third, it is well known that antihypertensive agents influence AI, BNP and cardiovascular parameters. In this study, we evaluated the relationship between AI and the BNP level receiving pharmacological therapy. The possibility that pharmacological therapy has different effects on the relationship between AI and BNP level cannot be excluded.

In conclusion, this study showed that, in PAF patients, an increased $\mathrm{AI}$, which is an index of wave reflection and arterial stiffness, was independently associated with the elevation of BNP level. LV diastolic dysfunction, which was linked to an increase in AI, may be involved in the BNP level. Furthermore, patients with greater LA size reflecting the progress of PAF showed greater arterial stiffness, suggesting that the development of PAF may be involved in the increase in arterial stiffness.

\section{CONFLICT OF INTEREST}

The authors declare no conflict of interest.

\section{ACKNOWLEDGEMENTS}

The authors thank Naoko Orita and Ryoko Shionohata for their excellent technical assistance, and the members of the SKY research group (Sumitomo Besshi Hospital, Kagawa Prefectural Central Hospital and Yashima General Hospital) for stimulating discussions.

1 Yoshimura M, Yasue H, Okumura K, Ogawa H, Jougasaki M, Mukoyama M, Nakao K Imura $\mathrm{H}$. Different secretion patterns of atrial natriuretic peptide and brain natriuretic peptide in patients with congestive heart failure. Circulation 1993; 87: 464-469.

2 Lubien E, DeMaria A, Krishnaswamy P, Clopton P, Koon J, Kazanegra R, Gardetto N, Wanner $\mathrm{E}$, Maisel AS. Utility of B-natriuretic peptide in detecting diastolic dysfunction: comparison with Doppler velocity recordings. Circulation 2002; 105: 595-601.

3 Ndrepepa G, Braun S, Niemoller K, Mehilli J, von Beckerath N, von Beckerath O, Vogt W, Schömig A, Kastrati A. Prognostic value of $\mathrm{N}$-terminal pro-brain natriuretic peptide in patients with chronic stable angina. Circulation 2005; 112: 2102-2107.

$4 \mathrm{Li} \mathrm{J}$, Wang L. B-type natriuretic peptide levels in patients with paroxysmal lone atrial fibrillation. Heart Vessels 2006; 21: 137-140.

5 Doi M, Miyoshi T, Hirohata S, Iwabu A, Tominaga Y, Kaji Y, Kamikawa S, Sakane K, Kitawaki T, Kusano KF, Kusachi S. Increased augmentation index of the radial pressure waveform in patients with paroxysmal atrial fibrillation. Cardiology 2008; 113: $138-145$

6 Murgo JP, Westerhof N, Giolma JP, Altobelli SA. Aortic input impedance in normal man: relationship to pressure wave forms. Circulation 1980; 62: 105-116.

7 Izzo Jr JL. Arterial stiffness and the systolic hypertension syndrome. Curr Opin Cardiol 2004; 19: 341-352. 
8 Weber T, Auer J, O'Rourke MF, Kvas E, Lassnig E, Berent R, Eber B. Arterial stiffness, wave reflections, and the risk of coronary artery disease. Circulation 2004; 109: 184-189.

9 Oliver JJ, Webb DJ. Noninvasive assessment of arterial stiffness and risk of atherosclerotic events. Arterioscler Thromb Vasc Biol 2003; 23: 554-566.

10 Shinohata R, Nakatsu T, Yuki Y, Nishitani A, Mashima K, Toyonaga S, Ogawa H, Hirohata S, Usui S, Kitawaki T, Kusachi S. Association of augmentation index of radial pressure wave form with diurnal variation pattern of blood pressure in untreated patients with essential hypertension. J Hypertens 2008; 26: 535-543.

11 Hashimoto J, Watabe D, Hatanaka R, Hanasawa T, Metoki H, Asayama K, Ohkubo T, Totsune K, Imai Y. Enhanced radial late systolic pressure augmentation in hypertensive patients with left ventricular hypertrophy. Am J Hypertens 2006; 19: 27-32.

12 Shirai K, Utino J, Otsuka K, Takata M. A novel blood pressure-independent arterial wall stiffness parameter; cardio-ankle vascular index (CAVI). J Atheroscler Thromb 2006; 13: $101-107$

13 Izuhara M, Shioji K, Kadota S, Baba O, Takeuchi Y, Uegaito T, Mutsuo S, Matsuda M. Relationship of cardio-ankle vascular index (CAVI) to carotid and coronary arteriosclerosis. Circ J 2008; 72: 1762-1767.

14 Kubozono T, Miyata M, Ueyama K, Nagaki A, Otsuji Y, Kusano K, Kubozono O, Tei C. Clinical significance and reproducibility of new arterial distensibility index. Circ J 2007; 71: 89-94.

15 Sakane K, Miyoshi T, Doi M, Hirohata S, Kaji Y, Kamikawa S, Ogawa H, Hatanaka K, Kitawaki T, Kusachi S, Yamamoto K. Association of new arterial stiffness parameter, the cardio-ankle vascular index, with left ventricular diastolic function. J Atheroscler Thromb 2008; 15: 261-268.

16 European Heart Rhythm Association; Heart Rhythm Society, Fuster V, Rydén LE, Cannom DS, Crijns HJ, Curtis AB, Ellenbogen KA, Halperin JL, Le Heuzey JY, Kay GN, Lowe JE, Olsson SB, Prystowsky EN, Tamargo JL, Wann S, Smith Jr SC, Jacobs AK, Adams CD, Anderson JL, Antman EM, Hunt SA, Nishimura R, Ornato JP, Page RL, Riegel B, Priori SG, Blanc JJ, Budaj A, Camm AJ, Dean V, Deckers JW, Despres C, Dickstein K, Lekakis J, McGregor K, Metra M, Morais J, Osterspey A, Zamorano JL, American College of Cardiology; American Heart Association Task Force on Practice Guidelines; European Society of Cardiology Committee for Practice Guidelines; Writing Committee to Revise the 2001 Guidelines for the Management of Patients With Atrial Fibrillation. ACC/AHA/ESC 2006 guidelines for the management of patients with atrial fibrillation - executive summary: a report of the American College of Cardiology/American Heart Association Task Force on Practice Guidelines and the European Society of Cardiology Committee for Practice Guidelines (Writing Committee to Revise the 2001 Guidelines for the Management of Patients With Atrial Fibrillation). J Am Coll Cardiol 2006; 48: 854-906.

17 Chalmers J. The 1999 WHO-ISH Guidelines for the management of hypertension. Med J Aust 1999; 171: 458-459.

18 Hayward CS, Kelly RP. Gender-related differences in the central arterial pressure waveform. J Am Coll Cardiol 1997; 30: 1863-1871.

19 Kelly R, Hayward C, Avolio A, O'Rourke M. Noninvasive determination of age-related changes in the human arterial pulse. Circulation 1989; 80: 1652-1659.
20 World Medical Association Declaration of Helsinki. Recommendations guiding physicians in biomedical research involving human subjects. Cardiovasc Res 1997; 35: 2-3.

21 Cheitlin MD, Armstrong WF, Aurigemma GP, Beller GA, Bierman FZ, Davis JL, Douglas PS, Faxon DP, Gillam LD, Kimball TR, Kussmaul WG, Pearlman AS, Philbrick JT, Rakowski H, Thys DM, Antman EM, Smith Jr SC, Alpert JS, Gregoratos G, Anderson JL, Hiratzka LF, Faxon DP, Hunt SA, Fuster V, Jacobs AK, Gibbons RJ, Russell RO, ACC; AHA; ASE. ACC/AHA/ASE 2003 Guideline Update for the Clinical Application of Echocardiography: summary article. A report of the American College of Cardiology/ American Heart Association Task Force on Practice Guidelines (ACC/AHA/ASE Committee to Update the 1997 Guidelines for the Clinical Application of Echocardiography). J Am Soc Echocardiogr 2003; 16: 1091-1110.

22 Appleton CP, Galloway JM, Gonzalez MS, Gaballa M, Basnight MA. Estimation of left ventricular filling pressures using two-dimensional and Doppler echocardiography in adult patients with cardiac disease. Additional value of analyzing left atrial size, left atrial ejection fraction and the difference in duration of pulmonary venous and mitral flow velocity at atrial contraction. J Am Coll Cardiol 1993; 22: 1972-1982.

23 Devereux RB, Reichek N. Echocardiographic determination of left ventricular mass in man. Anatomic validation of the method. Circulation 1977; 55: 613-618.

24 Sakuragi S, Maruo T, Taniguchi M, Nagase S, Nakamura K, Kusano KF, Ohe T. Radial augmentation index associated with increase in B-type natriuretic peptide in patients with hypertension. Int J Cardiol 2008; 130: 414-419.

25 McEniery CM, Yasmin, Hall IR, Qasem A, Wilkinson IB, Cockcroft JR. Normal vascular aging: differential effects on wave reflection and aortic pulse wave velocity: the AngloCardiff Collaborative Trial (ACCT). J Am Coll Cardiol 2005; 46: 1753-1760.

26 Williams B, Lacy PS, Thom SM, Cruickshank K, Stanton A, Collier D, Hughes AD, Thurston H, O'Rourke M, CAFE Investigators; Anglo-Scandinavian Cardiac Outcomes Trial Investigators; CAFE Steering Committee and Writing Committee. Differential impact of blood pressure-lowering drugs on central aortic pressure and clinical outcomes: principal results of the Conduit Artery Function Evaluation (CAFE) study. Circulation 2006; 113: 1213-1225.

27 Borlaug BA, Melenovsky V, Redfield MM, Kessler K, Chang HJ, Abraham TP, Kass DA. Impact of arterial load and loading sequence on left ventricular tissue velocities in humans. J Am Coll Cardiol 2007; 50: 1570-1577.

28 Weber T, O'Rourke MF, Ammer M, Kvas E, Punzengruber C, Eber B. Arterial stiffness and arterial wave reflections are associated with systolic and diastolic function in patients with normal ejection fraction. Am J Hypertens 2008; 21: 1194-1202.

29 Hashimoto J, Westerhof BE, Westerhof N, Imai Y, O'Rourke MF. Different role of wave reflection magnitude and timing on left ventricular mass reduction during antihypertensive treatment. J Hypertens 2008; 26: 1017-1024.

30 Takaki A, Ogawa H, Wakeyama T, Iwami T, Kimura M, Hadano Y, Matsuda S, Miyazaki Y, Matsuda T, Hiratsuka A, Matsuzaki M. Cardio-ankle vascular index is a new noninvasive parameter of arterial stiffness. Circ J 2007; 71: 1710-1714.

31 Vaziri SM, Larson MG, Benjamin EJ, Levy D. Echocardiographic predictors of nonrheumatic atrial fibrillation. The Framingham Heart Study. Circulation 1994; 89: 724-730. 